\title{
Tinajas con decoración estampada de época almohade de Quesada (Jaén)
}

\author{
Ma Magdalena Riera Frau * \\ Guillermo Rosselló Bordoy *** \\ Natalia Soberats Sagreras *****
}

Los reiterados hallazgos de cerámica con decoración estampada que se vienen realizando en una zona próxima al núcleo urbano de Quesada (Jaén) han permitido reunir, a lo largo de los años, una importante colección de fragmentos de cerámica en la Casa de Cultura del Ayuntamiento del mencionado lugar. Los hallazgos en superficie se realizan en una zona situada al pie de la muralla medieval que se conoce con el nombre de "Los pechos de Santa María". Esta zona, situada al norte de la ciudad, nunca ha sido prospectada sistemáticamente, sin embargo el material recogido permite plantear suficientes hipótesis como para ser objeto de estudio por si mismo. '

No parece probable que "Los pechos de Santa María" fueran sólo el solar del vertedero local de residuos urbanos, ya que el material de deshecho doméstico no presentaría la unidad formal, tipológica y cronológica que se observa en los fragmentos localizados. Si a estos factores se añade el hallazgo de un sello de los utilizados para estampar motivos decorativos sobre la cerámica la conclusión a que se llega es que tales fragmentos proceden del testar de un alfar que podría estar situado en las inmediaciones de aquel lugar.
El análisis de los fragmentos recogidos, pertenecientes al mismo tipo de recipiente: tinajas, realizados con el mismo barro y decorados con los mismos sellos y punzones permite completar la definición de la producción de este alfar y su cronología.

La producción se concreta en tinajas decoradas con estampado combinado con otros tipos de decoración. La morfología de estas tinajas no puede establecerse todavía, únicamente puede afirmarse que se trata de contenedores de cuello cilíndrico y labio de perfil cuadrangular o triangular. El diámetro de la boca y el cuello se sitúa en torno a los veinte centímetros. Las tinajas andalusíes mantienen las mismas dimensiones en el cuello y borde de las piezas independientemente del volumen que puedan contener. Deben ser cuellos anchos y fuertes para permitir la manipulación del contenido de la tinaja y para poder mantener en posición invertida los contenedores vacíos. ${ }^{2}$ Por todo ello, aunque sea posible establecer la morfología de los cuellos de las tinajas de Quesada de ello no puede derivarse, por comparación tipológica, el resto de su forma.

* Sevicio Municipal de Urbanismo de Palma de Mallorca; *** Director del Museo Arqueológico de Palma de Mallorca; **** Museo Arqueológico de Palma de Mallorca.

I Agradecemos a Manuel Vallejo, Director de la casa de Cultura de Quesda, todas las facilidades prestadas para realizar el presente estudio.

2 Son pocas las tinajas andalusíes de perfil y decoración reconstruibles, halladas en un contexto estratigráfico bien definido. A título de ejemplo véanse las de Caños de Meca, Cádiz (Cavilla, 1992); Los Guájares, Granada (Cressier et alii, 1991), Mértola (Torres, 1996); La Chanca, Almería (Torres Balbás, 1957); Palma de Mallorca (Rosselló, 1978) o Jijona, Alicante (Azuar, 1985 b). 
La cronología de la producción de Quesada puede establecerse por analogía con el resto de las producciones de al-Andalus que se circunscriben a los periodos almohade y nazarí. ${ }^{3}$ En el caso de Quesada la conquista cristiana de 1247 marcaría el final de una producción que se habría iniciado en un momento no determinado de la segunda mitad del siglo XII. ${ }^{4}$

La totalidad de los fragmentos hallados corresponden a contenedores realizados con el mismo tipo de barro, que da como resultado una cerámica de color amarillento, compacta y de textura pulverulenta. Sobre el barro verde se realizaba la decoración. En los ejemplares de Quesada el estampillado era el eje central de la decoración que se completaba y mejoraba con otras técnicas:

- Aplicación de cordones de barro que adoptaban formas onduladas y que, a su vez, eran decoradas con incisiones realizadas a cuchillo o con punzones.

- Decoraciones incisas realizadas a mano alzada con un punzón romo.

- Pintado de los fondos de los motivos estampillados con pintura al almagre o al manganeso.

- Impresión sin relieve de las estampillas sobre un fondo pintado al almagre o al manganeso. Este tipo de decoración es propio de la producción de Quesada, siendo en este momento difícil establecer cual era el sistema utilizado para obtener estas impresiones.

Con la cantidad de fragmentos recogidos hasta la actualidad es posible establecer un corpus inicial de motivos reproducidos mediante dos técnicas de estampado o de impresión que pueden considerarse propios de la producción de Quesada, que no se encuentran en ninguna de las demás producciones conocidas y que se encuentran solamente en fragmentos de tinaja hallados en lo que consideramos el área de dispersión de las tinajas de Quesada.
Los temas decorativos son muy variados. Destacan en primer lugar aquellos de tipo epigráfico, bien en escritura cúfica, bien en escritura nasjí. Con harta frecuencia una u otra grafía se combinan en una misma tinaja. Esta circunstancia puede tener un relativo valor cronológico pues la escritura nasjí no se populariza en al-Andalus hasta finales del siglo XII, (LÉVI-PROVENÇAL, 1931, 34) por tanto las estampillas con este tipo de escritura no podemos situarlas en fases anteriores. El cúfico, en cambio, puede perdurar hasta tiempos avanzados, perdiendo por tanto su valor cronológico. Tan sólo aquellas tinajas decoradas con estampillas de distinta grafía podrán proporcionarnos una situación en el tiempo relativa.

Los motivos epigráficos se combinan con otros de carácter vegetal o geométrico. En general estos motivos parecen subsidiarios de los motivos epigráficos, salvo las series de motivos en forma de arco apuntado completado con motivos vegetales o manos de Fátima.

De todas maneras, no es posible establecer una clara relación jerárquica en la utilización de cada uno de los punzones ni establecer si existía un programa decorativo complejo al tratarse de un conjunto de fragmentos de pequeñas dimensiones en los que apenas caben uno o dos motivos decorativos y por lo general fragmentados.

\section{Análisis de las estampillas}

Pensamos, en especial a partir del conocimiento de las estampillas utilizadas en el alfar de Quesada que en un momento dado se fabricó un conjunto homogéneo de matrices originales, posiblemente de madera, a partir de los cuales se produjeron un número indeterminado de punzones de características idénticas, con el fin de facilitar los trabajos de estampación.

La realización de dichos punzones pudo introducir variantes que deformaron o altera-

\footnotetext{
3 Ver apéndice bibliografico sobre tinajas almohades.

4 Carriazo Arroquia, Juan de Mata: Colección diplomática de Quesada.
} 
ron el tema original, produciendose cambios imperceptibles que generan una variedad temática evidente en los fragmentos estudiados.

Tales cambios pudieron muy bien producirse tambien según el grado de cuidado al aplicarlos sobre el barro verde, no solo a causa de la precisión y presión sino en cuanto a la relación del tamaño de la estampilla con el diámetro del sector de la tinaja donde aquella es aplicada.

En todo caso la idoneidad de la estampación puede matizarse con retoques ulteriores: perfilado de fondos para resaltar el tema (frecuente en los ejemplares de Quesada), hasta aplicación de pintura oscura en el fondo para resaltar el tema decorativo.

Un sello o matriz en cerámica, a causa de su fragilidad, tuvo que tener una vida de difícil evaluación. Roto el original se pudo, muy bien, obtener una copia a partir de una impronta en positivo, trastocando de este modo el sentido original del tema decorativo. Esto no es problema en temas geométricos o vegetales, pero puede evidenciarse en temas epigráficos: almulk convertido en kalima. No es frecuente pero posible. En algunas ocasiones se puede obtener lecturas de dificil interpretación o letreros poco habituales en la temática decorativa por no decir fuera de lugar por completo.

En aquellas matrices donde se aprecia la combinación de varios temas decorativos: epígrafes y complementos vegetales, posiblemente fuera operativo diferenciar ambos para una mayor claridad.

La propuesta seguida en este primer intento de normalizar la presentación de las estampillas almohades de Quesada tiene como punto de partida resaltar el tema, sea de la naturaleza que sea, en oscuro, dejando en blanco el fondo. De momento ha sido para nosotros el sistema más claro y más operativo en nuestro estudio.

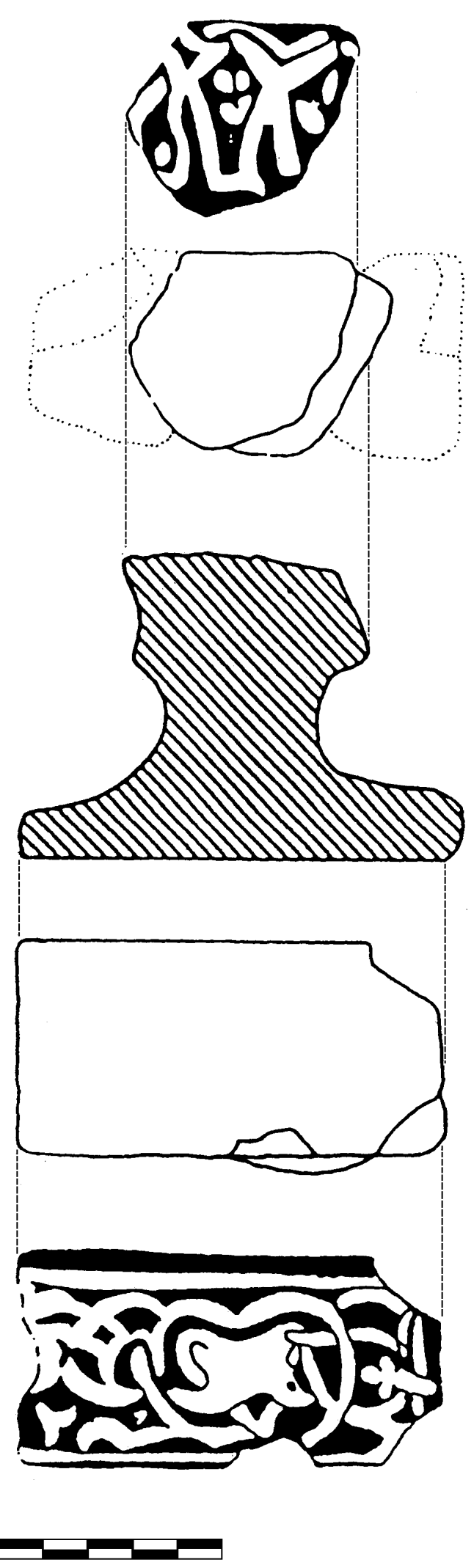

La estampilla de Quesada (Rosselló - Soberats, 1990) 


\section{Descripción de las estampillas.}

A efectos de clasificación distinguimos los punzones de acuerdo con las siglas siguientes:

QUESADA, como indicativo del lugar de fabricación o en su caso del hallazgo.

\section{Epigráficas:}

QUESADA E - I.।: Tema epigráfico: al-mulk = el poder, en escritura cúfica simple. A nivel epigráfico podríamos indicar que su trazado es arcaizante a causa del prodominio de trazos rectos. Línea de escritura marcada por el arranque basal del alif del artículo mientras que los ápices superiores de alif, lam y kaf rematan en formas triangulares. Nexos de enlace curvos, sin rebasar la línea de escritura, circunstancia que motiva que la mim y la kaf se desarrollen a partir de una línea intermedia. El espacio sobre la mim se complementa con un tema vegetal a base de una doble curva foliada. Un elemento curvilíneo se aprecia bajo esta misma letra (tal vez sea un simple artificio para conseguir una continuidad de la línea de escritura). La kaf se halla rodeada de pequeñas hojas triangulares y geminadas. Su presencia es muy frecuente entre los materiales de Quesada y las variantes gráficas obtenidas de estampillas diferentes asi lo demuestran.

QUESADA E I.2:

Tema epigráfico: al mulk = el poder, en escritura cúfica evolucionada. Línea de escritura marcada por el ápice inferior de la alif del artículo. Nexos curvos y rectos que elevan el nexo mim lam por encima de la línea de escritura. Kaf evolucionada. Ápices superiores en forma triangular. Decoración complementaria de motivos geométricos.

QUESADA E - 1.3:

Tema epigráfico: al-mulk = el poder, en cúfico evolucionado tosco. Línea de escritura marcada por ápice basal del alif del artículo con nexos quebrados que se extienden por debajo de ella. Apices superiores de forma triangular. Decoración complementaria vegetal estilizada.
Una letra para distinguir el tema decorativo: $\mathbf{E}=$ epigráfico, $\mathbf{G}=$ geométrico, $\mathbf{V}=$ vegetal $y$ $X$ para las escasas manifestaciones que no pueden ser englobadas en la anterior clasificación. Los números individualizan cuños, variantes, etc.
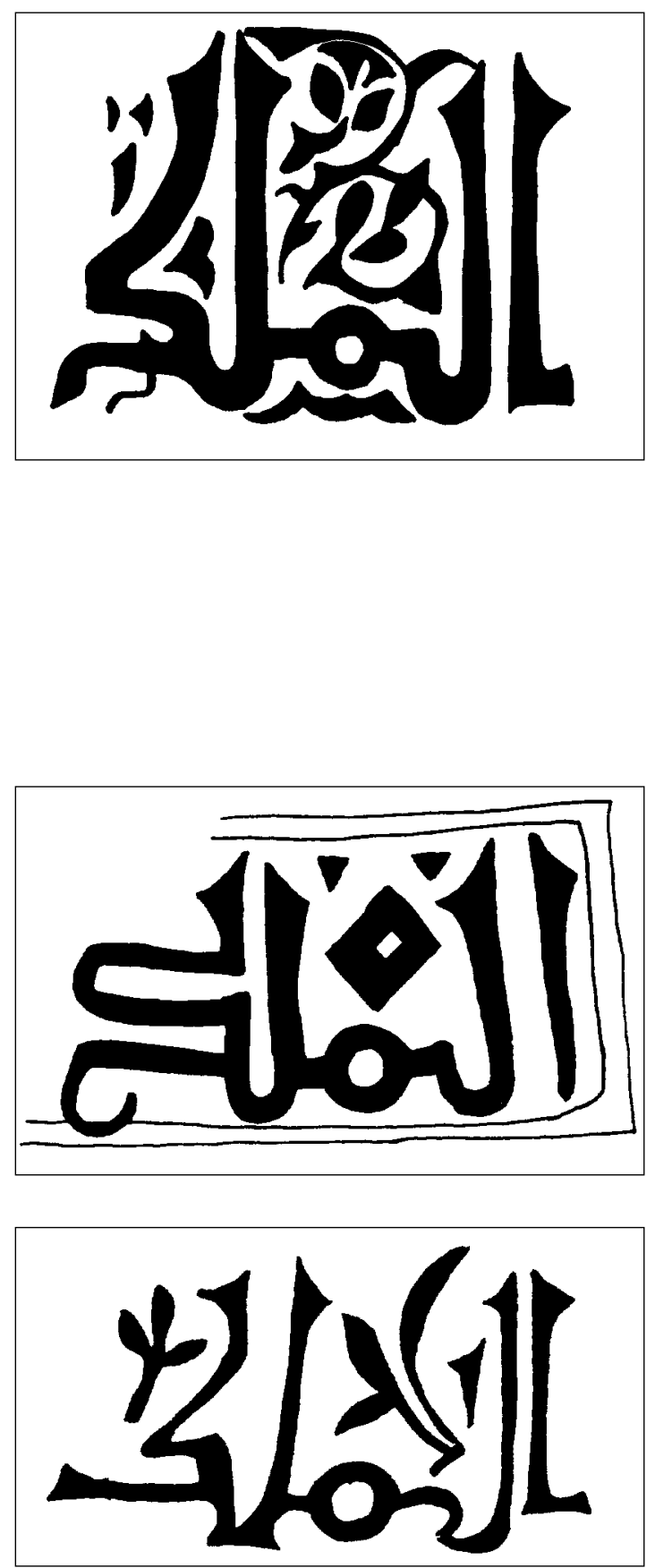
QUESADA E - 1.4:

Tema epigráfico: al mulk = el poder, en escritura cúfica algo evolucionada. Línea de escritura marcada por apéndice basal de la alik del artículo. Nexo curvo que se desliza por debajo de ésta entre lam i kaf. Apéndices superiores triangulares. Elementos vegetales y geométricos completan la decoración.

QUESADA E - I.5:

Tema epigráfico: al mulk = el poder, en escritura cúfica algo evolucionada. Línea de escritura marcada por apéndice basal del alif del artículo. Nexo curvo entre lam y kâf apenas se aprecia por debajo de la línea de escritura. Apéndices superiores muy complicados, en especial el de la kâf final. Tema vegetal en espiral sobre la mîm.

QUESADA E - 2:

Tema epigráfico: al-kalima = la palabra, en escritura cúfica simple, de carácter arcaizante. Linea de escritura marcada por el arranque basal de la alif del artículo. Apices superiores de aliz, mim, lam, kaf y tâ' marbûta rematan en forma triangular, nexos rectos a partir de línea intermedia. Tâ' marbûta esquemática, reducida a una simple vertical con ápice inferior en curva abierta. Solamente se ha detectado en una ocasión entre los materiales de Quesada. La palabra al-kalima no es un motivo epigráfico habitual en época almohade, cuando lo frecuente, documentado en Mértola, sería el uso de la palabra kâmila = completa, siempre como calificativo de otra palabra (Khawli, 1993). Ello hace pensar en una transposición de una matriz al-mulk retocada y reconvertida en al-kalima o en un error del grabador que al intentar escribir la palabra kâmila (= completa) unió el alif de prolongación de la primera silaba a la siguiente letra mim, desvirtuando la función ortográfica del alif. De todos modos de aceptar esta propuesta faltaría la terminación de femenino en tâ' marbûta, que no se aprecia en este cuño. Compárese con lo que se dirá al tratar de la matriz Quesada E - 8. Elementos decorativos complementarios de carácter vegetal rodean la kaf en el espacio enmarcado por las dos lam. La mim presenta una superposición en vertical a base de dos elementos circulares que mimetizan la forma de la letra con apéndices en horizontal.
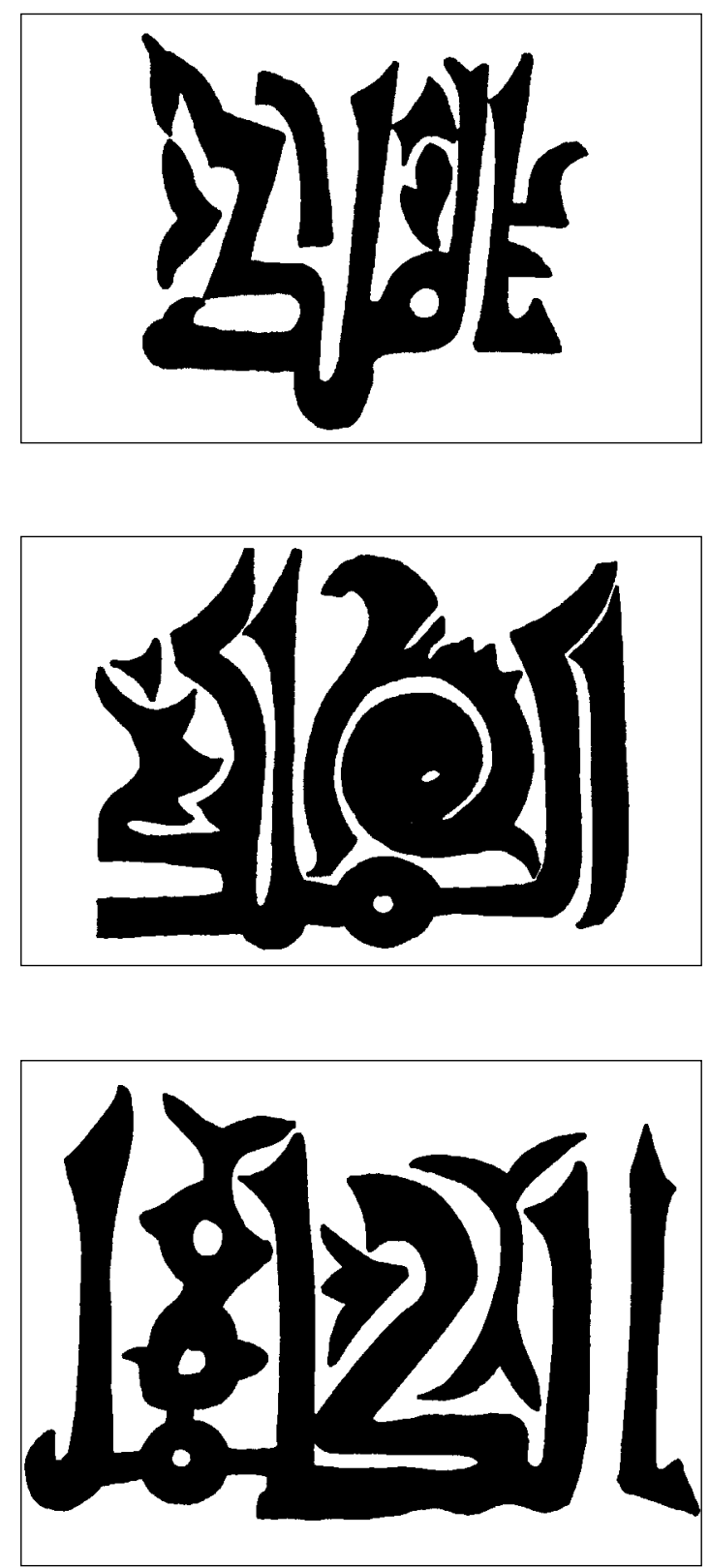
QUESADA E - 3:

Tema epigráfico: al-'afiya = la felicidad, en escritura cúfica evolucionada con tendencia a perfiles redondeados. Linea de escritura única con nexos curvos. Apices superiores de alik, lam y ta'marbuta rematan en forma triangular. Sobre la 'ayn se superpone un elemento cuadrangular que mimetiza la forma de esta letra, rematado el espacio por una hoja geminada. Motivos geométricos sobre la fâ'y yâ'. La ta' marbûta parece más bien un nexo lam-alif.

QUESADA E - 4.I: Tema epigráfico: al-yumn = la prosperidad, en escritura cúfica evolucionada que aun mantiene una tendencia hacia lo rectilíneo. Línea de escritura marcada por apéndice basal del alif. Los ápices superiores de las letras son de forma triangular incluso la mîm adopta una forma romboidal maciza y se halla en una posición intermedia. Nexos curvos y rectos. Motivo complementario de estrellas aisladas sobre la mim y la nun. Posiblemente el fragmento no proceda del alfar de Quesada pues la textura y coloración del barro es diferente.

\section{QUESADA E - 4.2.1:}

Tema epigráfico: al-yumn = la prosperidad, cúfico muy evolucionado con tendencia al sistema cursivo o nasjí. Rasgos de trazado tosco, que permiten individualizar las diferentes letras. Nexos curvos y rectos a partir de línea de escritura imprecisa. Sobre la mîm motivo vegetal simple: hojita triple.

QUESADA E - 4.2.2: Estampilla epigráfica de interpretación dudosa. Escritura cúfica con la palabra al-yumn, más una letra final que pudiera ser una tâ' marbûta, cosa harto improbable, o bien un rasgo curvo del ápice inferior del alif con que se inicia la palabra siguiente. La mîm , muy abierta no está grabada de manera clara y prescisa. Se complementa el registro decorativo con un tema vegetal foliado

QUESADA E - 4.3:

Tema epigráfico: al yumn.... = la prosperidad, en escritura nasjí evolucionada. Puede considerarse una variante muy estilizada. El alif del artículo monta sobre la nûn final que ha sido grabada de una forma poco usual, quebrando el trazo final que corre por la parte inferior de la palabra yumn. Motivos vegetales se desarrollan en las zonas intermedias.
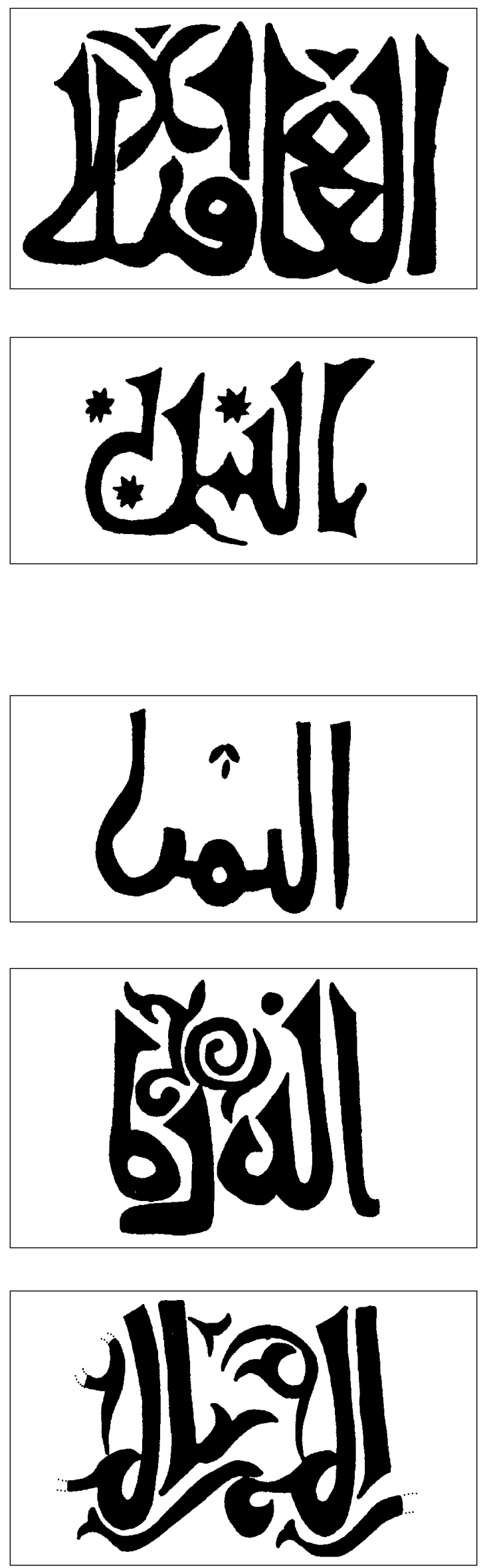
QUESADA E - 5.1:

Tema epigráfico, incompleto: al-yumn wa al-iq[bâl] = la prosperidad y la felicidad, en escritura cursiva (nasji) poco evolucionada, de perfiles curvos. El tema se desarrolla en dos líneas superpuestas al-yumn y sobre la yâ'-mîm se situa la waw. El nexo alif-lâmalif de la segunda palabra se superpone sobre la nûn final de la primera palabra. La letra qaf se mantiene aislada a modo de waw quedando interrumpida la palabra. Las diferentes letras quedan perfectamente individualizadas.

QUESADA E - 5.2: Tema epigráfico: [a]l-yumn wa al-iqbâl = la prosperidad y la felicidad, en escritura cúfico nasjí que podríamos considerar como transicional. Falta el alif del artículo de la primera palabra. Lâm con ápice superior triangular y el cuerpo de la palabra yumn formado por una curva con nudo central que no individualiza las tres letras. Waw conjuntivo de trazado curvo y nexo lam-alif-lam en cúfico redondeado. La segunda parte de la palabra en cursiva muy estilizada. Lam final reducida a una simple curva. Estampilla que suele aparecer casi exclusivamente en el cuello de las tinajas, sobre fondo pintado negro.

QUESADA E - 6:

Tema epigráfico: baraka = bendición, en escritura cúfica tosca, algo evolucionada. Línea de escritura con prolongaciones por debajo de la misma, Nexos trazados de forma recta y curva indistintamente. Kaf evolucionada y tâ' marbûta esquemática. Motivos complementarios geométrico vegetales dispuestos en cruz. No parece ser obra del alfar de Quesada por calidad y coloración del barro. Elementos vegetales curvilíneos complementan la decoración.

QUESADA E - 7: Tema epigráfico: ash-shukr ... = la recompensa [de Allah ?], en escritura cúfica evolucionada con tendencia al cúfico florido. Línea de escritura marcada por el trazo basal de la kaf y por debajo de ella se desplaza la alif. El ápice inferior de la râ' final y los nexos curvos entre lam-shin y shin-kaf. Esta última muy historiada. Un tema vegetal curvilíneo, muy complejo ocupa el espacio superior del campo epigráfico. Una linea mixta enmarca la parte inferior del lema epigráfico.

\section{5}
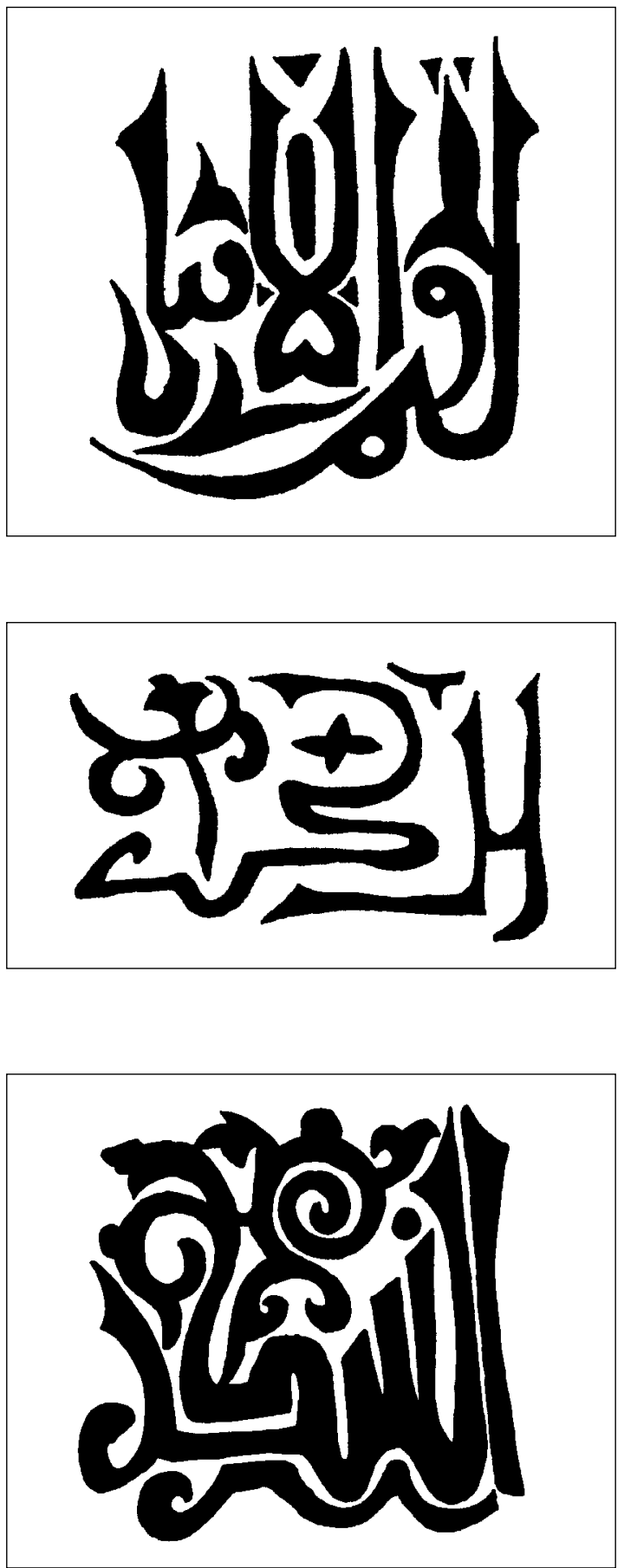
Las estampillas que se relacionan a continuación aun siendo de carácter epigráfico son de interpretación dudosa, bien por estar fragmentadas, bien por tratarse de lemas poco frecuentes en la decoración propia de la época

QUESADA E - 8:

Estampilla epigráfica en escritura cúfica. Incompleta pues solo se conserva la parte central de la inscripción que puede interpretarse como [a]l-kâ[mila] = completa, adjetivo que suele acompañar a otras palabras que no se pueden determinar en esta ocasión, aunque por comparación con textos similares impresos en tinajas halladas en Mértola (Khawli, 1993) podríamos interpretar como kâmila li-sâhibi-hi = completa para su amo o kâmila kâfíya = felicidad completa o simplemente baraka kâmila = bendición completa, localizada en diferentes puntos de al-Andalus. (Véase lo dicho al tratar de QUESADA E - 2.)

QUESADA E - 9: Estampilla epigráfica en cúfico simple. Interpretación dudosa por tratarse de una palabra sin identificar y no habitual entre las eulogias usadas en este tipo de decoración.

\section{Temas no epigráficos}

Los motivos no epigráficos localizados a lo largo de las investigaciones de Quesada pueden ser simples o complejos. Entre los primeros cabe destacar los de carácter geométrico: círculos, estrellas, motivos aspados muy esquemáticos que pueden ser interpretados como variantes vegetales foliadas. Entre los segundos hay que destacar las decoraciones vegetales que debidamente combinadas pueden producir un efecto arquitectónico pues a la larga mimetizan algo así como arquerías polilobuladas sobre pilastras, conseguidas mediante hábiles cortes hechos a cuchillo, temática que conocemos en otros lugares (Khawli, 1994) y que en Quesada, si se consigue el efecto, no es a base de la aplicación de la estampilla adecuada, sino con el complemento de otras técnicas decorativas. o, tal vez, por escritura incorrecta de determinadas palabras, circunstancia poco probable, pues la correcta escritura de los escribas es proverbial, aunque no pueda descartarse tal posibilidad.
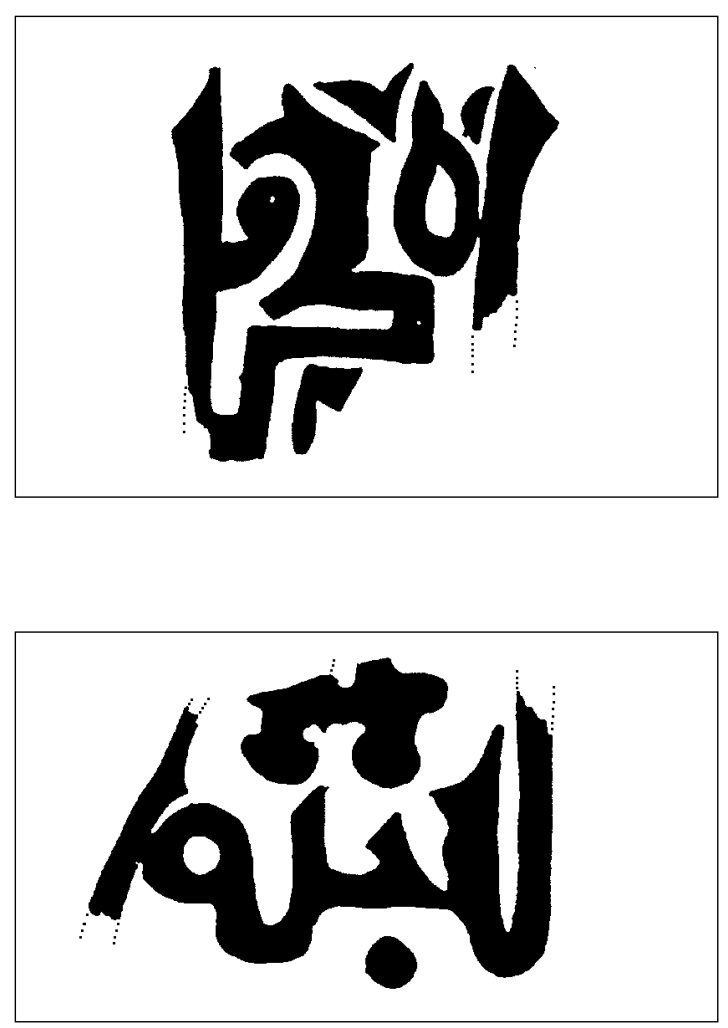

Si en una primera impresión pudimos hablar de temas arquitectónicos, ahora después de un análisis más meticuloso es conveniente cambiar esta apreciación. De todos modos no hay que rechazar de plano la existencia de matrices de caracter arquitectónico definidas de manera clara a partir de las estampillas halladas en Mértola.

Individualizar los temas decorativos que se engloban en este apartado no es tarea fácil, pues a las deficiencias normales de impresión, desgaste de las matrices, etc. se añade la superposición de estampillas combinadas para producir un efecto estético muy variado que el alfarero sabe retocar con precisión con la ayuda de instrumentos rústicos, metálicos o de madera, que no han llegado a nosotros. 
Temas vegetales

QUESADA V - I:

Tema vegetal muy esquemático a partir de un eje de simetría, rematado en su àpice superior por un motivo aspado. A ambos lados, disimétricos, dos cartelas curvas, muy toscas con una espiral en relieve que se une al punto inferior. Todo inserto en una cartela trilobulada. Por características externas consideramos que no es del alfar de Quesada.

QUESADA V - 2: Cartela rectangular abierta por abajo. En el centro doble motivo floral asimétrico separado por un elemento acorazonado que sirve de eje de simetría. El motivo central puede definirse como una variante del as de picas de la baraja francesa. Uno de los dos aparece en relieve, mientras el otro se halla rehundido. En los ángulos de la cartela, a modo de bisectriz hay unos motivos estilizados: recta-curva en un caso, espiral en otro.

QUESADA V - 3: Friso de motivos foliados o acorazonados, irregulares y asimétricos, con predominio de la línea curva, todo en relieve.

QUESADA V - 4: Greca curvilínea de tipo vegetal, a base de un tallo en doble curva con ápices foliados y hojas insertas en el tallo. Todo en cartela rectangular, abierta por un lado. El motivo decorativo aparece en relieve.

QUESADA V - 5 Motivo vegetal muy estilizado a base de florones en relieve de forma acorazonada y colocados en posición invertida uno respecto al otro. El tema aparece enmarcado por dos trazos horizontales, superior e inferior, en relieve, quedando abierto en los lados para facilitar la impresión continuada de la misma matriz.
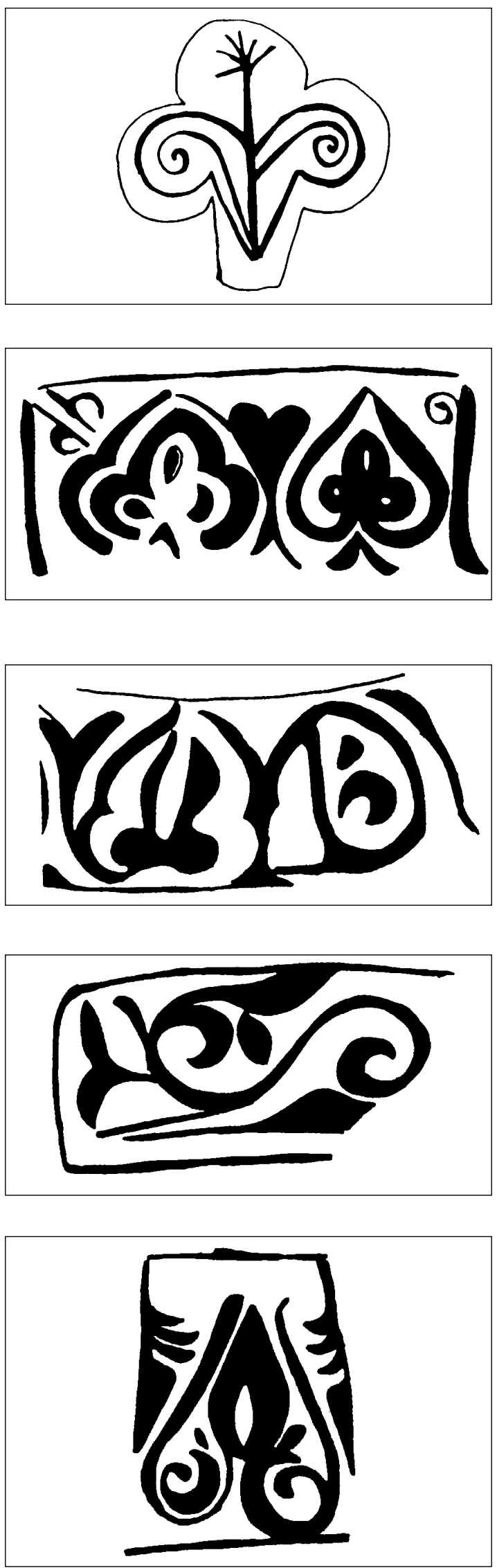
QUESADA V - 6:

Motivo vegetal simple a base de motivo acorazonado hecho mediante líneas curvas. El cuño presenta un motivo central con el ápice hacia arriba flanqueado por la mitad del motivo en disposición contrapuesta. Pequeñas hojas acorazonadas cierran los espacios libres

\section{QUESADA V - 7:}

Motivo vegetal complejo, inserto en cartela rectangular. Distribuido en dos filas: en la superior se aprecia un doble motivo acorazonado, abierto por abajo y en su interior un elemento romboidal, hojitas curvas en los espacios intermedios. En la inferior trazos verticales con ensanchamiento central o superior alternan con círculos rematados en punta por su ápice superior y un motivo angular en la zona inferior.

\section{QUESADA G - I:}

Cartela rectangular a base de rombos inscritos unos en otros partiendo de un motivo central generado por una línea sinuosa cerrada. A su alrededor se repite el tema partido por el eje: dos módulos en los lados largos y uno en los estrechos. Da la impresión que era una estampilla para obtener una línea continuada con este tema. Hay que destacar la tosquedad de su trazado.

QUESADA G - 2:

Cartela rectangular rebordeada por elementos rectos de distinto grosor. En su interior una línea quebrada estructura el espacio en tres sectores rellenos con temas foliados hechos a base de trazos rectos con la incorporación de algunas hojas de perfil curvo.
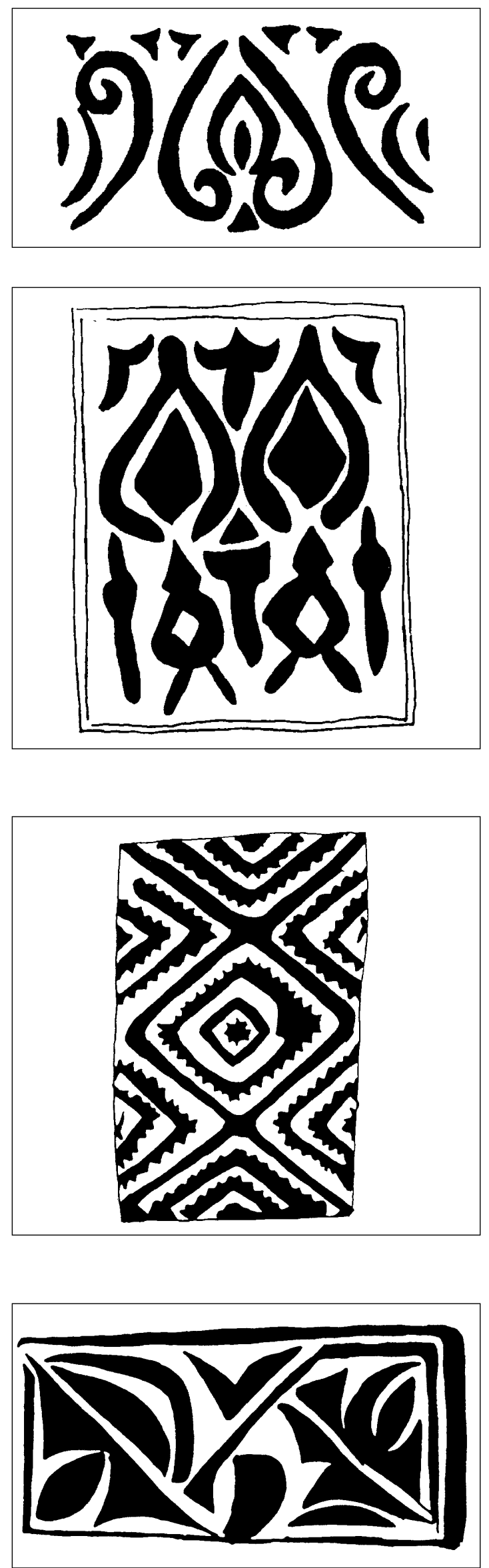
QUESADA G - 3:

Cartela rectangular en relieve que presenta en su centro y en hueco un triple motivo circular inscrito, compuesto por un botón en relieve y dos circunferencias concéntricas generadas por triangulitos contrapuestos. Bordeando este motivo, en los ángulos de la cartela, estrellas incisas de ocho puntas con botón central en relieve.

QUESADA G - 4: Estampilla rectangular en relieve que enmarca un trazo, inciso, semicircular, que cubre un motivo floral de cinco pétalos romos, generados a partir de un circulito central diferenciado por línea en relieve.

QUESADA G - 5: Corresponde a temas a base de estrellas aisladas que combinadas una a una pueden formar una especie de greca.

Motivos estrellados simples: Diferentes variantes de estrella inserta en cartela cuadrangular. Todas ellas son de ocho puntas, generados a partir de punto central en relieve diferenciándose en la forma de sus ápices: aspado, romo, patado.

QUESADA G - 6:

Motivos estrellados complejos. Se trata de elementos aislados formados cada uno de ellos por estrella de ocho puntas hechas a base de elementos geométricos bien diferenciados. La 6.I presenta las puntas a modo de hojas romas en relieve con punto central, todo inserto en línea ondulada que sigue el perfil de los ápices. La 6.2 está formada por ocho puntas romas insertas en cavidades incisas y el todo enmarcado por línea ondulada incisa a modo de sépalos. Una corona en relieve circunda el motivo. La 6.3 presenta ocho aspas romboideas, en relieve insertas en cavidad incisa.
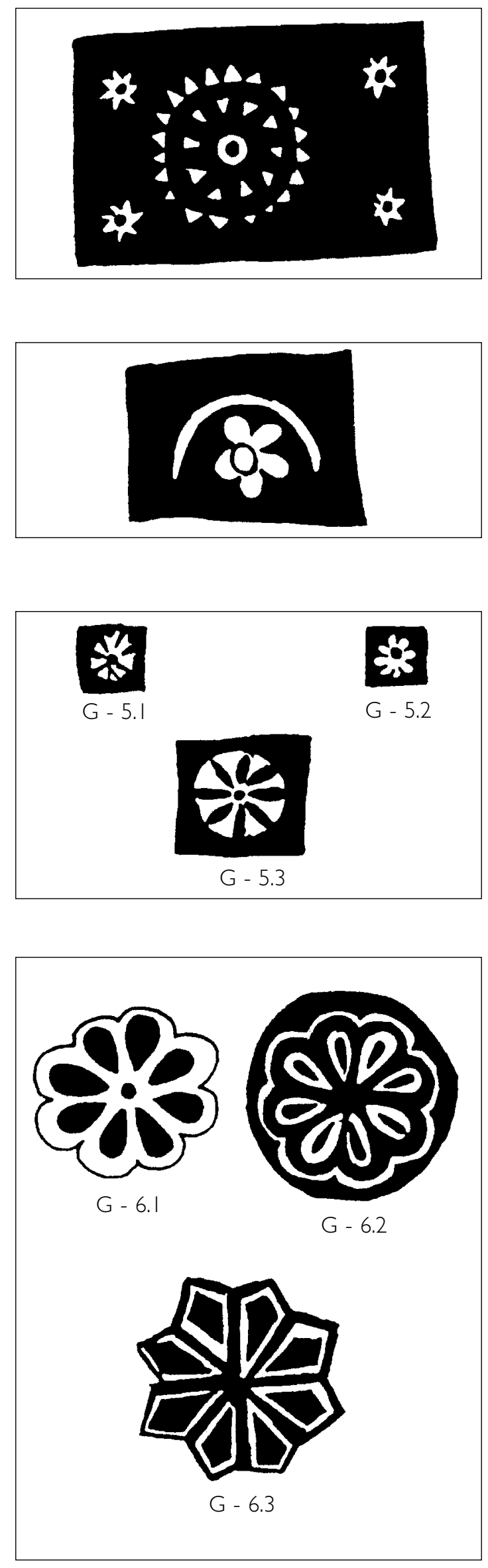
QUESADA G - 6.4:

Motivo estrellado, simple, de seis puntas rematadas en ápice recto. Estrella en negativo sobre florón circular inscrito en marco rectangular. Muy simple y de trazado incorrecto.

QUESADA G - 6.5

Motivo estrellado a partir de un núcleo central cuadrangular que genera triángulos equiláteros, contrapuestos, que delimitan unos espacios en blanco enmarcados por trazos curvos. En el espacio central se observa un motivo cruciforme de aspas curvas generadas a partir de un punto central. En los espacios triangulares hay puntos, uno de ellos inscrito en un círculo.

\section{Otros motivos decorativos:}

Otras estampillas de caracter mixto, debidamente complementadas con cortes al cuchillo pueden mimetizar una decoración arquitectónica. Por lo general combinan un elemento

QUESADA $X-1$ : Arco apuntado con motivos curvos y circulares en su interior y hojas en el exterior.

QUESADA $X$ - 2: Arco apuntado en relieve bordeado de circulillos dispuestos tres a los lados y uno en el ápice. En el interior del arco un motivo foliado simétrico. En los espacios exteriores estilizaciones que podrían ser una falsa epigrafía. El efecto producido al combinarse recuerda las arquerías polilobuladas.

QUESADA X - 3: Arco generado por dos curvas vegetales abiertas que encierran un motivo floral más o menos simétrico, hojas acorazonadas en el espacio exterior.
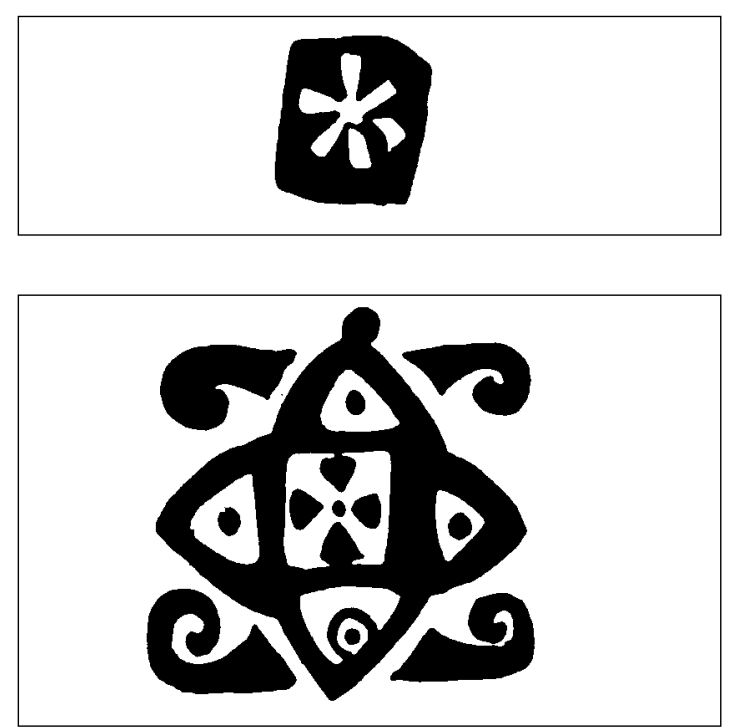

geométrico en arco apuntado con decoración complementaria vegetal o geométrica con predominio de las líneas curvas sobre las rectas.
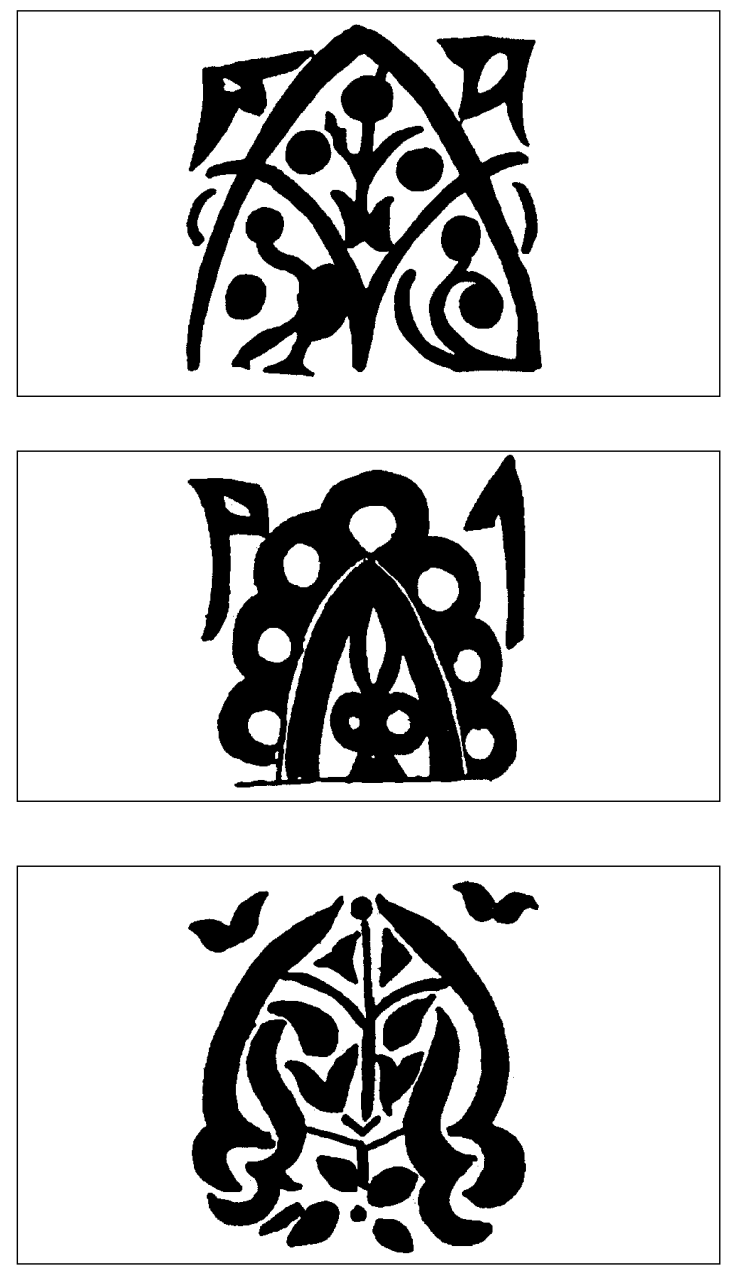
QUESADA X - 4:

Arco polilobulado asimétrico rebordeado por su parte superior con linea curva. En el interior mano de Fátima muy estilizado sobre trazos curvos.Todo enmarcado por trazos verticales. Es el único motivo quesadeño que puede relacionarse con un elemento de carácter arquitectónico.

\section{Dispersión de las tinajas de Quesada}

La comparación de los motivos de las estampillas de la producción de Quesada con las tinajas estampilladas localizadas hasta el momento en al-Andalus, nos ha permitido localizar varios

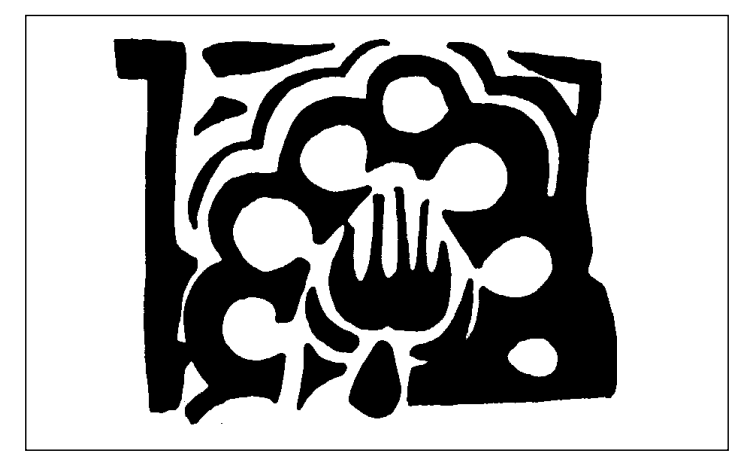

fragmentos que indudablemente corresponden a recipientes fabricados en Quesada. Estos fragmentos son:

I: Fragmento hallado en Calasparra (Murcia): corresponde a una tinaja decorada con motivos vegetales estampados y con cordones ondulados e incisos superpuestos. En su parte inferior presnta una inscripcion pre-cochura 'amal al-Qayshatî realizada a mano alzada con un punzón romo (Pozo, 1990, 28)

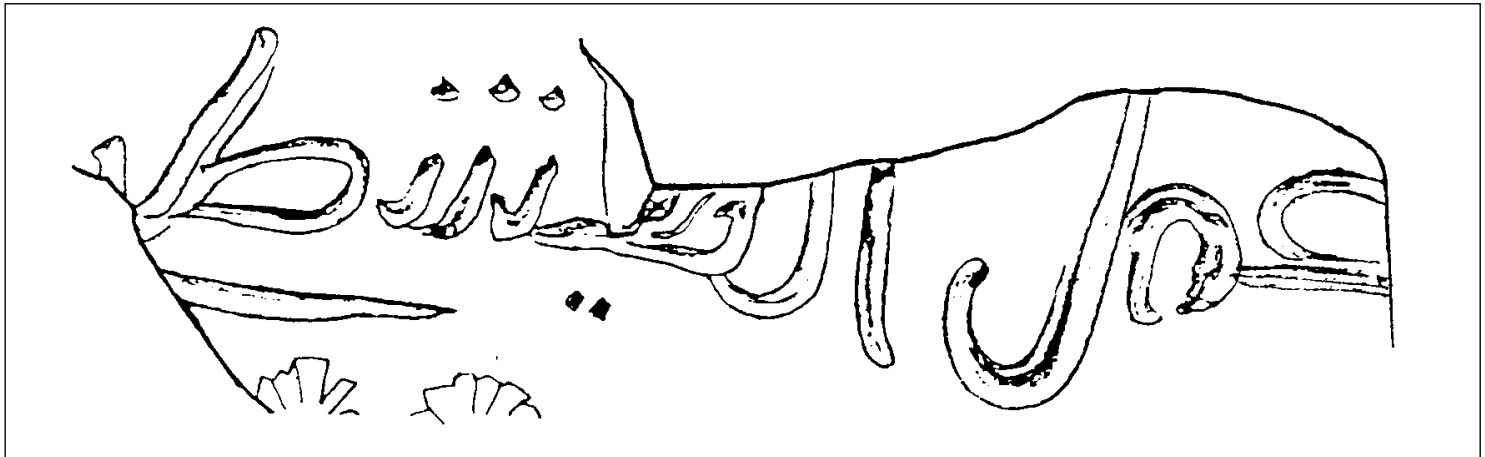

2: Fragmentos de borde de tinaja hallada en el casco urbano de Lorca decorada con la estampilla QUESADA 4.4.(Navarro, 1986, 68).

3: Fragmento de borde de tinaja decorada con la estampilla QUESADA E.I.I "al-mulk"= el poder, hallado en el casco urbano de Lorca (Murcia). (Navarro, 1986, 7I)

4: Base de tinaja decorada con la estampilla QUESADA E 7 : ash-shukr= la recompensa, localizada en un lugar determinado del término municipal de Lorca (Murcia) *Navarro, 1986, 127) 
Esta dispersión hacia la zona murciana es perfectamente coherente con las referencias a Quesada en las fuentes árabes. Al-Idrīī (S. XII) cita Quesada en la ruta que de Jaén a Murcia, que pasaba por Jódar, Quesada, Alicún, Galera, Vélez-Rubio, Lorca y Librilla. Dentro de su estudio sobre la ruta de los Velez, E. Motos señala la importancia de esta ruta

... no sólo al permitir el tránsito entre Andalucía y Levante, sino también en cuanto a que le permiten las relaciones con las ciudades, el intercambio comercial y la venta de los excedentes de sus propios productos, sobre todo en los mercados urbanos de Lorca y Murcia. el intercambio de mercancías y los estrechas relaciones con estas zonas murcianas pueden probarse también por la arqueología, por la similitud existente, por ejemplo, entre sus cerámicas y las encontradas en las zonas murcianas de donde tal vez proceden. (MOTOS, 1993, 1008-1009).

Una vez establecidas las características de la producción de tinajas estampilladas de Quesada y su área de dispersión conocida queda solamente por resolver el problema de la cronología de esta producción.

Parece indudable que la decoración estampillada de las tinajas hay que relacionarla con la época almohade. Los ejemplos a los que se adjudica una cronología anterior son pocos y, o bien carecen de contexto estratigráfico, como los fragmentos de Medina al-Zahra, (PABÓN, 1967) o bien son producciones mudéjares, como las tinajas de producción toledana. (AGUADO, 1991)

Por otra parte cabría también en su momento relacionar la producción de Quesada con la hipótesis recientemente planteada por Manuel Acién sobre la utilización de la cerámica como elemento de propaganda en época almohade (ACIÉN , 1996).

El estampillado permite la reiterada aplicación de leyendas y a su vez, en el caso de la producción de Quesada, se combina su uso con la pintura al manganeso.

M. Acién relaciona el esgrafiado murciano, en parte equivalente al estampillado sobre negro de Quesada, con el programa propagandístico de Ibn Hûd de Murcia:

Por otra parte, todos los autores que han tratado sobre la figura de Ibn Hud resaltan la legitimidad conseguida a través del califa 'abbasí mediante la adopción del antiguo título de los almorávides de amir al-muslimin, la acuñación de moneda a su nombre, las embajadas y los diplomas y laqab/s honoríficos otorgados, así como la utilización de enseñas 'abbasíes, entre ellos, la bandera de color negro.

En consecuencia, creo que no es tanto la temática, como opinaba Pierre Guichard, sino el dominante color negro del esgrafiado lo que explota Ibn Hûd como símbolo de su legitimidad y de su ruptura con los almohades. (ACIÉN, 1996).

Aunque esta hipótesis deberá ser contrastada con los hallazgos arqueológicos fuera de Murcia, es coincidente con el área de dispersión de las tinajas de Quesada, centrada en el área murciana.

Por lo que hace a la cronología de las tinajas estampilladas de Quesada no parece quedar ninguna duda de su adscripción a la época almohade, fabricándose hasta el momento de la conquista feudal de Quesada.

La aparición del fragmento de tinaja con la inscripción 'amal al-Qayshati permite establecer una especialización, incluso a nivel de autoría de la producción de Quesada

Este tipo de referencias a la autoría de las piezas son poco frecuentes en la cerámica andalusí, siendo exclusivas de algunas cerámicas de Madīna al-Zahrā' y de las tinajas almohades. $M$. Acién ha publicado dos fragmentos de tinaja con inscripciones similares pero realizadas al estampillar la tinaja, una con la inscripción 'amal Hasan=obra de Hasan y otra con la inscripción 'amal al-Qabtali=obra de al-Qabtali, procedentes de Ronda y Gibralfaro (Málaga). Estas referencias a la autoría de las piezas son interpretadas por M. Acién como:

una propaganda del taller o del artesano, que se puede entender como un reconocimiento de calidad, o, a un nivel más abstracto, como una 
especial concepción del sujeto autor de la obra, que era inconcebible en el feudalismo contemporáneo. Sin embargo, esta aseveración no nos debe llevar a relacionarlo con nuestros conceptos de artelartista, que son exclusivos de la burguesía. Recordemos que Ibn Jaldun no utiliza el término fann, sino el de sina'a (industria), englobando en él "artes" tan distintas de los nuestros como son las propias del agricultor o de la partera. (ACIÉN, 1996).

Esta especialización de la producción explicaría también que para el alfar de Quesada en un momento dado el grabador especializado en elementos gráficos trazara, de un modo peculiar y concreto, una teoría de estampillas o cuños adecuados a los gustos y maneras de este al-Qayșhatī que, gracias a un ensospechado hallazgo en Calasparra, podemos denominarlo de una manera precisa, aunque sea, solamente, a través de su gentilicio, el de Quesada...

Si hubo otros qayșhatíes dedicados al arte cerámico, cosa harto posible, no podemos asegurarlo.

Una definición cronológica y tipológica como la que hemos intentado con el alfar de Quesada es imprescindible para dar coherencia tanto a los estudios monográficos como a las referencias a hallazgos de tinajas estampilladas. Intentar identificaciones sin haber definido antes las producciones es un ejercicio tan inútil como el querer identificar otras producciones locales, como el verde y manganeso taifa, atendiendo sólo a motivos decorativos.

Ignoramos aun cuantos centros productores de tinajas estampilladas hubo en al-Andalus. De igual manera no podemos distinguir aún las producciones almohades de las nazaríes y mudéjares. Entre tanto, hacer los corpus de hallazgos de ámbitos geográficos generalmente relacionados con divisiones administrativas actuales tiene solo la validez de, cuando las producciones hayan quedado establecidas, poder conocer su zona de dispersión.

\section{BIBLIOGRAFÍA}

ACIÉN ALMANSA, M. (1996): "Cerámica y propaganda en época almohade", Arqueologia Medieval, 4, Mértola, pp. |83-19|.

AGUADO VILLALBA, J. (|99|): Tinajas medievales españolas. Islámicas y mudéjares, Toledo.

AZUAR RUIZ, R. (1985 a): "Cerámica islámica", excavaciones medievales en el Castillo de la Mola (Novelda-Alicante) I. Las cerámicas ginas (s. XII-XV), Novelda, pp. 81-87 y 12 I- 122.

AZUAR RUIZ, R. (1985 b): Castillo de la Torre Grossa (lijona). Catálogo de fondos del Museo Arqueológico. I., Alicante.

BAZZANA, A. y CRESSIER, P. (1989): Shaltish / Saltés (Huelva). Une ville médiéval d'al-Andalus, Madrid.

CAVILLA SÁNCHEZ-MOLERO, F. (1992): La cerámica hispano-musulmana de Beca. Los Caños de Meca. Barbate. Cádiz, Cádiz.

COLL CONESA, J. (1993): "Contenedores cerámicos medievales en las costas de Mallorca", IV CAME, Alicante, III, pp. 1069- I079.

COMBÉS, J. L. y A. (1967): Les potiers de Djerba, Tunis.

CORREIA, F. B. (|99|): "Um conjunto cerâmico árabemedieval de Beja", A cerâmica medieval no Mediterraneo occidental, Mértola, pp. 373-385.

CRESSIEr, P. et alii: "La cerámica tardoalmohade y los orígenes de la cerámica nasri", A cerâmica medieval no Mediterrâneo Occidental, Mértola, pp. 2/5-|46.

DELPY, A. (1955): "Note sur quelques vestiges de céramique recueillis a Salè", Hesperis, XLII, pp. I29-152.

DEVERDUN, G y ROUCH, M. (1949): "Notes sur de nouveaux documents de céramique marocaine découverte en Marrakech", Hesperis, XXXVII, pp. 45I-455.

DE LOS SANTOS GENER, S. (1948): "Estampillas de alfarerías moriscas cordobesas", Memorias de los Museos Arqueológicos Provinciales, IX-X, Madrid, 1948-1949, pp. 220-232.

DOMINGUEZ BEDMAR, M. y ESPINAR MORENO, M. (I99I): "Catalogación preliminar de estampillas almerienses", A cerâmica medieval no Mediterraneo occidental, Mértola, pp. 593-599.

FLORES ESCOBOSA, I. et alii (199|): Vivir en al Andalus. Exposición de cerámica (S. IX-XV), Almería, 1992.

GARRIDO GARRIDO, M. y GARCIA GRANADOS, J. A. (1987): "Introducción al estudio de la cerámica estampillada andalusí en Granada", II CAME, Madrid, pp. 677-687.

GOLVIN, L. (1965): Recherches arqueologiques à la Qal'a des Beni Hammad, París.

GOMES, R. V. (|99|): Cerâmicas almoadas do castelo de Silves", A cerâmica medieval no Mediterraneo occidental, Mértola, pp. 387-403. 
GHUNIM, K. A. (1994): La cerámica estampillada en Granada. Tesis doctoral, inédita. Universidad de Granada. Facultad de Filosofía y Letras, Granada.

HERRERA ESCUDERO, Ma. L. (1943): "Las tinajas mudejares del Museo de Toledo. Intento de sistematización", Memorias de los Museos Arqueológicos Provinciales, Madrid, pp. |46-।55.

KHAWLI, A. (1992): "Introduçâo ao estudo das vasilhas de armazenamento de Mértola islâmica", Arqueologia Medieval, II, Mértola, pp. 63-78.

KHAWLI, A. (1993): "Lote de cerâmica epigrafada em estampilhagem de Mértola", Arqueologia Medieval, III, Mértola.

KHAWLI, A. (1994): "Arcos estampilhados da cerâmica islâmica de Mértola", Arqueologia Medieval, III, Mértola.

LAVADO PARADINAS, P. (1978): "Dos fragmentos de una tinaja hispano-árabe hallados en Almería", BAEO, I4, Madrid, pp. 252-253.

LÉVI PROVENÇAL, E. (1931): Inscriptions arabes d'Espagne, Leyde - Paris.

MARÇAIS, G. (19|3): Les poteries et faïences de la Qal'a des beni Hammad, Constantine.

MARTINEZ CAVIRO, B. (|99|): Cerámica hispano-musulmana, Andalusí y mudéjar, Madrid.

MONTES MACHUCA, C. (1987): "Algunas cerámicas estampilladas de Jerez de la Frontera (Cádiz), Estudios de historia y arqueología, VII-VIII, Cádiz, 1987-1988, pp. 175- 195.

MOTOS GUIRAO, E. (1993): "De 'ad morum' a 'Balis'. El tránsito de la época romana a la medieval en la comarca de Los Vélez (Almería), IV CAME, III, Alicante, pp. I0051010.

NAVARRO PALAZON, J. (1986): La cerámica islámica en Murcia. Catálogo, Volumen I, Murcia.
NAVARRO PALAZÓN, J. (1987): "Formas arquitectónicas en el mobiliario cerámico andalusi", Cuadernos de La Alhambra, 23, Granada.

PAVÓN MALDONADO, B. (1967): "Notas sobre la cerámica hispanomusulmana", Al-Andalus, XXXII, Madrid-Granada, pp. 4I5-437.

PLEGUEZUELO, A. (1992): "Tinaja Almohade", Andalucía y el Mediterráneo, Cádiz, pp. 183-184.

POZO MARTÍNEZ, I. ( 1989): "El despoblado islámico de 'Villa Vieja', Calasparra (Murcia). Memoria preliminar", Miscelánea Medieval Murciana, XV, pp. 187-211.

POZO MARTÍNEZ, I. (1990): "Datos sobre el yacimiento musulmán de 'Villa vieja" (Calasparra), Ciclo de conferencias VII Centenario de Calasparra, Calasparra, s. P.

ROSSELLÓ BORDOY, G. y Soberats Sagreras, N. (1989): ¿Un alfar almohade en Quesada?, Quesada.

ROSSELLÓ BORDOY, G. (1978): Ensayo de sistematización de la cerámica árabe en Mallorca, Palma de Mallorca.

ROSSELLÓ BORDOY, G. (1990): Las cerámicas de primera época: algunas observaciones metodológicas, Granada.

SIERRA FERNÁNDEZ, J. A. y LASSO DE LA VEGA, M. G. (1982): "Tinajas mudejares del Museo Arqueológico de Sevilla. Tipología y decoración", Homenaje a Conchita Fernández Chicarro, Madrid, pp. 457-480.

TERRASSE, H. (I 937): "La céramique hispano-maghrebine du XII s. d'aprés les fouilles du chateau de Ain Ghaboulo", Hesperis, XXIV, Rabat, pp. I3-I8.

TORRES BALBÁS, L. (1957): "Restos de una casa árabe en Almería", Al-Ándalus, XXII, Madrid-Granada, pp. 4| I-457.

TORRES, C. (1992): Cerâmica islâmica portuguesa, Mértola.

TORRES, C., Passinhas da Palma, M., Rego, M., Macías, S. (1996): "Técnicas e utensílios de conservaçâo dos alimentos na Mértola islâmica", Arqueologia Medieval, 4, Mértola, pp. 203- 211. 


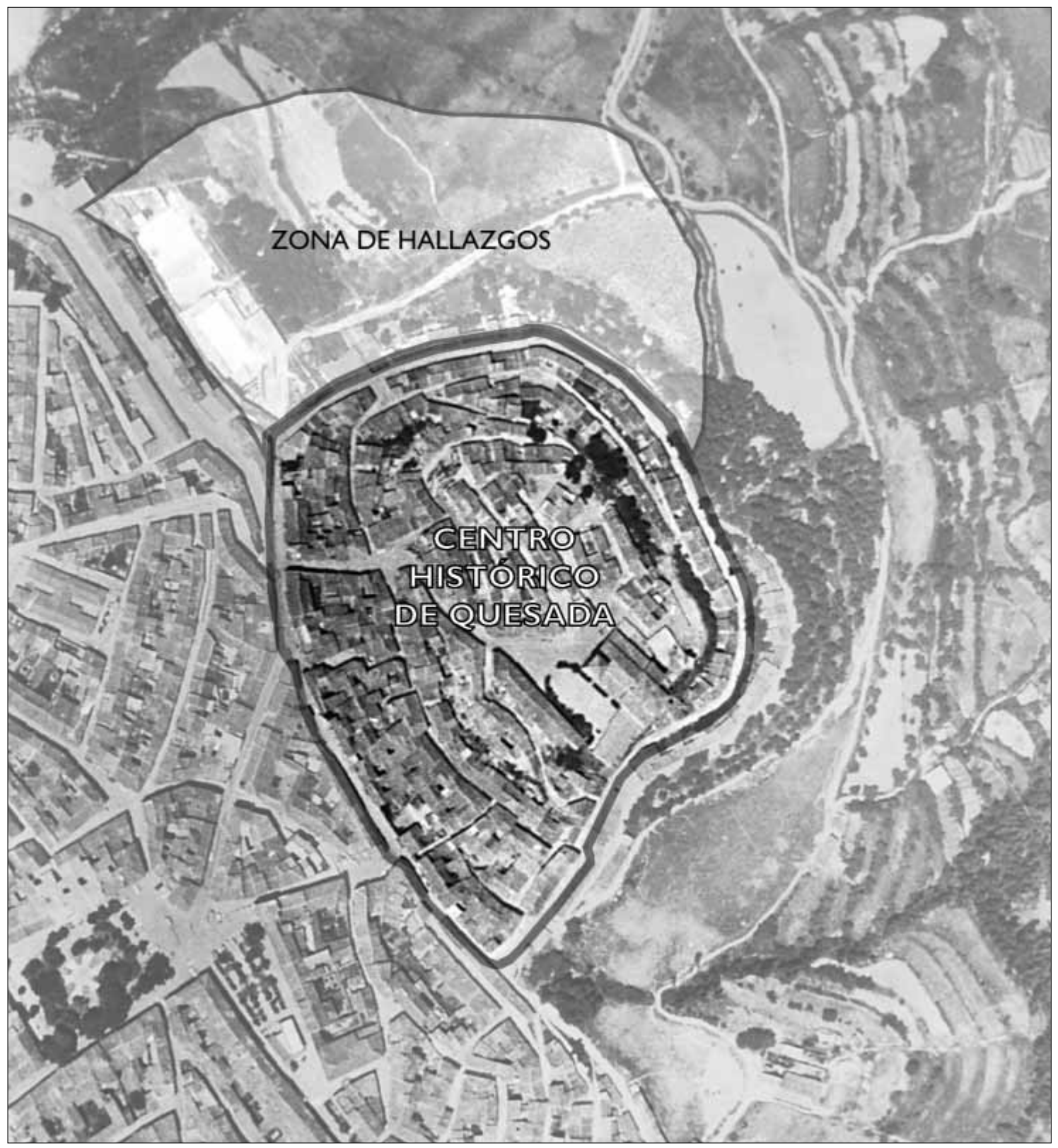

Fig. I. Localización de la zona de hallazgos. 